\title{
Endoscopic Septoplasty: A Novel Technique- A Case Series of 19 Cases
}

\author{
${ }^{1}$ Ranjan G Aiyer, ${ }^{2}$ Rahul Gupta, 3Jayman Raval \\ ${ }^{1}$ Professor and Head, Department of ENT and Head and Neck Surgery, SSG Hospital and Medical College, Baroda, Gujarat \\ India \\ ${ }^{2}$ Senior Resident, Department of ENT and Head and Neck Surgery, SSG Hospital and Medical College, Baroda, Gujarat, India \\ ${ }^{3}$ Junior Resident, Department of ENT and Head and Neck Surgery, SSG Hospital and Medical College, Baroda, Gujarat, India
}

Correspondence: Ranjan G Aiyer, Professor and Head, Department of ENT and Head and Neck Surgery, SSG Hospital and Medical College, 3/2 Jesal Apartment, Abhishek Colony, Race Cource, Vadodara-390007, Gujarat, India

\begin{abstract}
Endoscopic septoplasty is a rapidly evolving substitute to the customary "headlight" septoplasty. The primary advantage of the technique is the ability to reduce morbidity and postoperative swelling in isolated septal deviations by limiting the dissection to the area of the deviation. Other advantages include improved visualization, particularly in posterior septal deformities; improved surgical transition between septoplasty and sinus surgery and its use as an effective teaching tool. We present our experience with endoscopic septoplasty in a series of 19 patients.

Keywords: Endoscopic septoplasty, FESS, DCR.
\end{abstract}

\section{INTRODUCTION}

Septoplasty is the surgery for correction of deviated nasal septum under local or general anesthesia. It is a conservative surgery in which only deviated part is removed leaving behind as much cartilage and bone as possible. Conventional septoplasty is performed under standard headlight vision and involves septal correction after elevating the mucoperichondrial and mucoperiosteal flap.

Endoscopic septoplasty is a minimally invasive technique that helps us to correct septal deformities under direct endoscopic vision.

Endoscopic septoplasty is not only useful for treating symptomatic nasal obstructions but also for improving intraoperative surgical access to the middle meatus, as a preliminary step to endoscopic dacryocystorhinostomy and endoscopic sinus surgeries.

In addition improved visualization permits limited and minimally invasive surgery for isolated septal deviation or for revision surgery after septoplasty with persisting deviation. Minimal dissection results in less postoperative edema, less need for packing and decreased hospital stay period with early resumption of normal routine activity.

Endoscopic septoplasty is an excellent teaching tool when used in conjugation with video monitors and recording.

\section{METHODS}

The present study is of prospective type, conducted at the Department of Otorhinolaryngology at Medical College and Shree Sayaji General Hospital, Baroda between the period between June 2007 and July 2009.

All the patients presenting in the outpatient department of this hospital with symptomatic nasal septal deviations were examined systematically and suitable patients were selected for surgical management. All the patients in whom endoscopic septoplasty was performed as a preliminary step of another nasal surgery (e.g. FESS, DCR) were also included in this study.

A diagnostic endoscopy was routinely performed before the final surgery (Fig. 1). All the patients with significant infection in the nose were usually given a course of antibiotics and decongestants before planning surgery. Patients with nasal polyposis and fungal sinusitis were also given a preoperative trial of steroid sprays and antifungals. A patient with CSF rhinorrhea was observed for a period of 3 weeks with a conservative line of treatment before planning surgical intervention.

A computerized tomography (CT) scan was always advised for the patients being planned for functional endoscopic sinus surgery. 


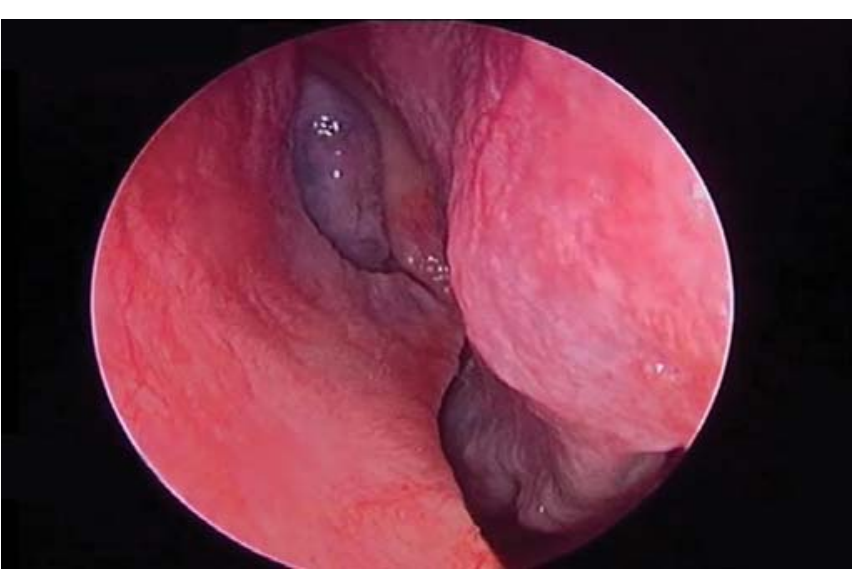

Figure 1: Preoperative endoscopic photograph showing a septal spur

\section{TECHNIQUE}

Position of patient: Supine position with head end elevated about 15 degrees.

Premedication: Atropine, Fortwin, Phenargan.

Nasal packing: Ribbon gauze soaked in $4 \%$ xylocaine solution with adrenaline.

\section{Anesthesia:}

1. Local with sedation.

2. General.

\section{Incision:}

1. Proximal to the most deviated portion of septum.

2. At the spur inferiorly in cases of isolated spur.

\section{Dissection:}

- Mucoperichondrial and mucoperiosteal flaps are elevated with Cottle's elevator under direct vision with the help of $0^{\circ}$ Telescope. Suction elevator can be a good substitute.

- The septal cartilage is then incised few millimeters posterior to the mucosal incision.

- The deviated portion is removed with the help of endoscopic scissors or forceps, taking care not to traumatize the opposite flap.

- Deviated portion of vomer or perpendicular plate of ethmoid are removed when necessary using a fine chisel.

- Powered instruments can be used, although care must be taken not to traumatize the adjacent mucosal tissue.

- Reconstruction of septum and closure of flap is delayed till the completion of sinus surgery.

- At this stage morselized cartilage can be replaced as needed.

- The postoperative photograph is shown in Figure 2.

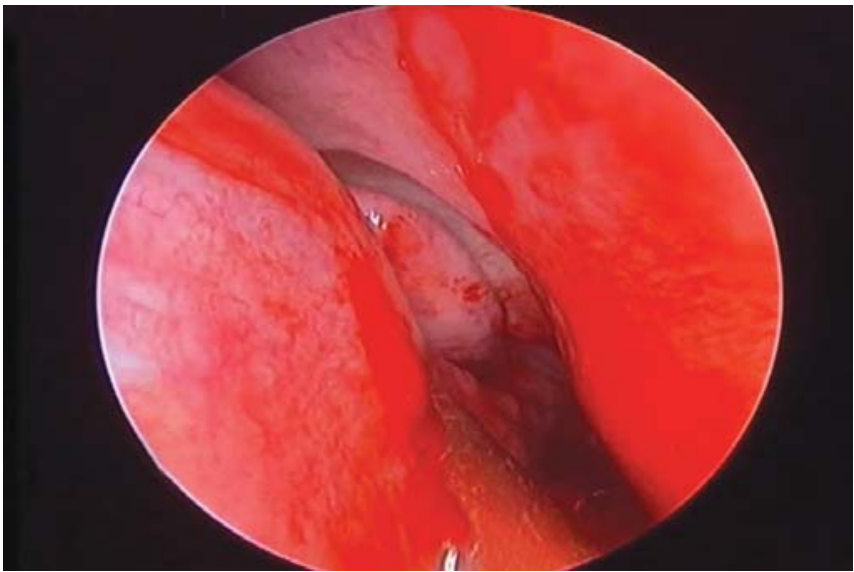

Figure 2: Postoperative endoscopic photograph after the removal of the spur

\section{RESULTS}

A total of 19 cases were operated for endoscopic septoplasty. In 6 of these no other procedure was performed. An isolated spur causing pressure over the lateral nasal wall was the usual indication for endoscopic septoplasty in these cases.

Septoplasty was carried out with FESS in 10 patients. Most of these had a septal deviation blocking the osteomeatal complex on the lateral nasal wall.

Two of the patients had a dacrocystorhinostomy performed and one had CSF leak repaired through the intranasal route. In all three of these patients septoplasty was required to provide space for instrumentation in the nasal cavity.

Two of these patients were operated in local anesthesia with intravenous sedation. Rests of the 17 patients were given general anesthesia.

Majority of the patients were discharged after an uneventful 6 hours postoperative period. All of them could resume routine household activities from the second day.

Some patients were discharged on the next morning. This usually included a few apprehensive patients who complained of pain.

All the patients were given a week of broad spectrum oral antibiotic like Cefatamet and Axylox with systemic analgesic and antihistaminic.

A single patient with CSF leak repair required prolonged hospital stay.

\section{DISCUSSION}

Septoplasty has come a long way from the time when punch forceps were used to remove the deviated part of septum to the recently performed powered functional endoscopic septal surgery (PENSS). ${ }^{1}$ Successful septoplasty involves 
accurate assessment of septal pathology and sound technique to avoid persistent symptoms and new complications. ${ }^{2}$ A conventionally performed septoplasty usually involves the elevation of mucoperichondrial flap in its whole length on one side followed by deviation correction. Conventional septoplasties have been routinely performed in our institution. Lanza et $\mathrm{al}^{3}$ and Stammberger ${ }^{4}$ initially described the application of endoscopic technique for the correction of septal deformity in 1991. Lanza et $\mathrm{al}^{3}$ described a detailed endoscopic approach to the treatment of isolated septal spur. The present study of endoscopic septoplasty was performed to study its indications, advantages/disadvantages and to study its role as an approach to various others endoscopic nasal surgeries.

Compared with standard headlight septoplasty, endoscopic technique provides several important advantages which include excellent visualization under direct light, less operative time, adequate correction of posterior septal deformities and improved evaluation of septal deformities in nasal valve region. It provides better access to the middle meatus space for FESS.

Endoscopic septoplasty can be used for following indications:

1. Isolated septal spur deformity.

2. Posterior septal deformity.

3. Correction of nasal valve obstruction.

4. Septal spur with contact area with persistent headache.

5. Stuffy nose along with turbinoplasty.

6. Approach to other endoscopic surgeries like endoscopic DCR, FESS.

7. Atypical facial pain with deviation.

8. Any septal deviation involving area of inspiratory and expiratory air flow causes more nasal obstruction.
The following benefits were found in endoscopic septoplasty:

1. Better visualization under direct light with endoscope.

2. Least invasive, only deviated part mucoperichondrium/ mucoperiosteum elevated.

3. Posterior septal spur correction is better which is difficult to reach/ missed by conventional method.

4. A reduced amount of blood loss.

5. Improves access to other endoscopic nasal surgeries.

6. Minimal tissue handling results in less postoperative edema and pain.

7. No complications like septal perforation and septal hematoma.

8. Packing is usually not required.

9. Day care surgery.

10. Early return to work.

11. Less expensive.

12. Uneventful postoperative period.

13. Excellent teaching tool for postgraduate and undergraduate students through recording and display. Finally we can say, especially in the cases of nasal septal surgery "less may be more".

\section{REFERENCES}

1. Acta Med Port powered endoscopic nasal septal surgeryaderito de sousa f, livia inciarte f, howard levine 2005;18:249-56.

2. Current Opinion in Otolaryngol Head Neck Surg. Endoscopic septoplasty.Getz AE, Hwang PH Feb 2008;16(1):26-31.

3. Lanza DC Kennedy DW, Zinreich, SJ. Nasal endoscopy and its surgical application in Lee KJ ed. Essential otolaryngology. Head and neck surgery (5th ed) medical examination New york 1994;373-87.

4. Stammberger H. Functional Endoscopic Sinus Surgery. The Messerklinger technique BC Decker Philadelphia 1991;432-33. 